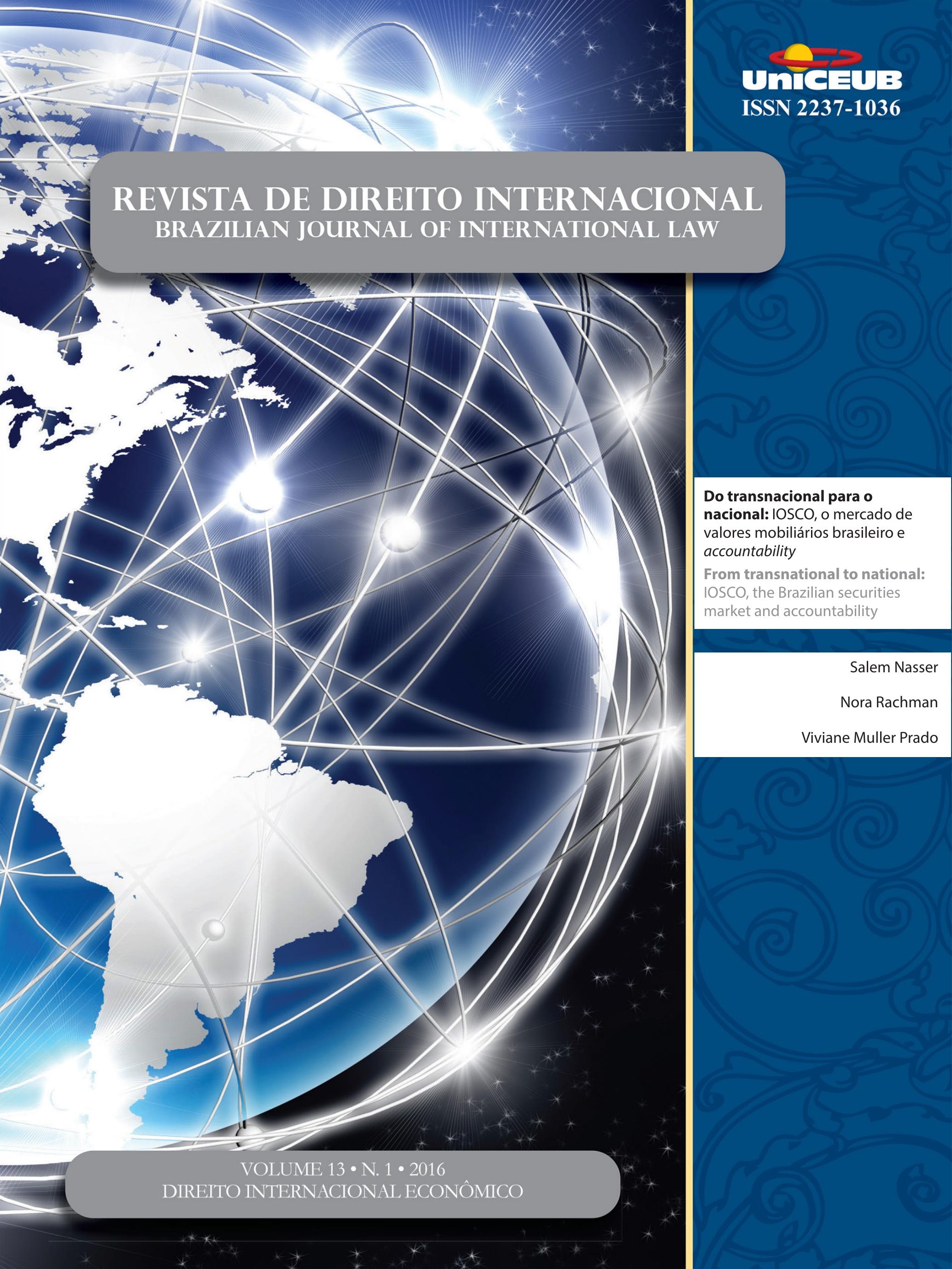




\section{Sumário}

Dossiê Temático: Direito Internacional Econômico.........................................................1

EDITORIAL:

Resultados da III Conferência Bienal da Red DEI ................................................. 3

Michelle Ratton Sanchez-Badin (em nome da Diretoria da Red DEI), Fabio Costa Morosini e Lucas da Silva Tasquetto (em nome dos organizadores da III Conferência da Red DEI)

Direito Internacional Econômico no Brasil: QUem Somos E o QUE faZemos? EvidênCIas EMPÍRICAS DE 1994 A 2014

Michelle Ratton Sanchez Badin, Fabio Costa Morosini e Inaê Siqueira de Oliveira

UM ESPAÇO PARA PENSAR EM ALTERNATIVAS? A ACADEMIA LATINO-AMERICANA DE DIREITO INTERNACIONAL ECONÔMICO FRENTE À ORDEM ECONÔMICA GLOBAL

Nicolás Marcelo Perrone

Grupo de alto Nível Brasil - Urugua (GAN): um Novo paradigma para a INTEgraÇão PRODUTIVA NO MERCOSUL

Alebe Linhares Mesquita e Vivian Daniele Rocha Gabriel

O COMÉRCIO de SERVIÇOS ENTRE Brasil E URUGUAI: LiberalizaÇÃo, DESAFIOS E PERSPECTIVAS DO SETOR DE TECNOLOGIA DA INFORMAÇÃO E COMUNICAÇÃO (TIC) E SOFTWARES

Vivian Daniele Rocha Gabriel e Alebe Linhares Mesquita

Core Labor Standards No Regime de PREFERÊNCIAS TARIFÁrias No MERCOSUL: A NeCESSIDADE DE HUMANIZAÇÃO DO COMÉRCIO INTERNACIONAL

Martinho Martins Botelho e Marco Antônio César Villatore

ACordo TRIMS: FleXibilizaÇão ou Não? Política de CONTEÚdo loCal, PROCESSO PROdUTIVO BÁSICO (PPB) E OS DESAFIOS PARA A INDÚSTRIA BRASILEIRA E A INTEGRAÇÃo LATINO-AMERICANA 100

Natália Figueiredo 
ESTUDIOS DE CASO DE RECHAZOS EN FRONTERA DE EXPORTACIONES ALIMENTARIAS LATINOAMERICANAS POR MOTIVOS RELACIONADOS CON MEDIDAS TÉCNICAS NO ARANCELARIAS.

Sofía Boza, Juan Rozas e Rodolfo Rivers

América do Sul em face dos tratados bilaterais de inVESTimento: RUMO aO RETORNo do EsTADO NA SOLUÇão DE CONTROvÉRSIAS? 133 Magdalena Bas

FutURo DE LOS SISTEMAS NACIONALES DE CIENCIA TECNOLOGÍA E INNOVACIÓN EN LA AGENDA ECONÓMICA DE AMÉRICA LATINA: DEFINIENDO CAMBIOS REGULATORIOS O PROTEGIENDO INVERSIONES 146

Rodrigo Corredor

EL PAPEL DE LAS INSTITUCIONES DE CONTROL FINANCIERO SOBRE LOS DERECHOS HUMANOS EN EL CONTEXTO LATINOAMERICANO 157 Jose Miguel Camacho Castro

CONVERGENCIA REgUlATORIA EN LA ALIANZA DEL PACÍFICO: UN CAPÍTULO INCONCLUSO 170 Rodrigo Polanco Lazo

O CONSTITUCIONALISMO E A COMUNITARIZAÇÃO NO DIREITO INTERNACIONAL: POSSIBILIDADES PARA O COMÉRCIO INTERNACIONAL?

Camilla Capucio

ESCASSEZ HÍDRICA E DIREITO INTERNACIONAL ECONÔMICO: O BRASIL COMO PROTAGONISTA NA TRANSFERÊNCIA DE ÁGUA PARA REGIÕES ÁRIDAS

Douglas de Castro

A Segurança energética como base para maior integração na América Do Sul: à espera DE UM TRATADO MULTILATERAL

Matheus Bassani

Outros Artigos. 246

As PRÁtICAS RESTRITIVAS DA CONCORRÊNCIA NO MERCADO DE CONTRATAÇÃo PÚBLICA EUROPEU .. 248 Alice Rocha da Silva e Ruth M. P. Santos 
Do TRANSNACIONAL PARA O NACIONAL: IOSCO, O MERCADO DE VALORES MOBILIÁRIOS BRASILEIRO E ACCOUNTABILITY

Salem Nasser, Nora Rachman e Viviane Muller Prado

MigRaÇÃo de TRABALHADORES INTELECTUAIS BRASILEIROS PARA O MERCADO INTERNACIONAL: IDENTIFICAÇÃO DE ATOS DE ALICIAMENTO DE EMPREGADOS E MECANISMOS LEGAIS PARA IMPEDIR A APROPRIAÇÃo TECNOLÓGICA E CONCORRÊNCIA DESLEAL ..........................................285 José Carlos Vaz e Dias e João Marcelo Sant'Anna da Costa

THE EASIER WAY TO HAVE "BETTER LAW"? THE MOST-SIGNIFICANT-RELATIONSHIP DOCTRINE AS THE FALLBACK CONFLICT-OF-LAW RULE IN THE PEOPLE'S REPUBLIC OF CHINA

Chi Chung

REFLEXOS JURÍDiCOS DA GOVERNANÇA GLOBAL SUBNACIONAL: A PARADIPLOMACIA E O DIREITO INTERNACIONAL: DESAFIO OU ACOMODAÇÃO 320

Valéria Cristina Farias e Fernando Rei

Matrizes Políticas da JUSTiÇA PENAL INTERNACIONAL. 341 Francisco Rezek

RESPONSABILIDAD INTERNACIONAL DEL ESTADO FRENTE A LUCHA CONTRA LA DISCRIMINACIÓN RACIAL Y ÉTNICA EN ESPAÑA. 348

Edilney Tomé da Mata e Eduardo Biacchi Gomes Correio

The Peace Process in Sierra Leone: an analysis on marriages between culture and CRIME

Gustavo Bussmann Ferreira

Funcionalização e expansão do Direito Penal: o Direito Penal negocial ...............376 Antonio Henrique Graciano Suxberger e Dermeval Farias Gomes Filho

Proteção Internacional do Consumidor e Cooperação Interjurisdicional .396 Héctor Valverde Santana e Sophia Martini Vial

The land rights of indigenous and traditional peoples in Brazil and Australia.... 418 Márcia Dieguez Leuzinger e Kylie Lyngard 
The reception of European ideas in Latin America: the issue of the German sources in Tobias Barreto, A Prominent nineteenth CENTURy BraZilian legal scholar........439 Arnaldo Sampaio de Moraes Godoy

Normas Editoriais ..................................................................................... 461 


\title{
Do transnacional para o nacional: IOSCO, o mercado de valores mobiliários brasileiro e accountability*
}

\section{From transnational to national: IOSCO, the Brazilian securities market and accountability}

\author{
Salem Nasser ${ }^{* *}$ \\ Nora Rachman*** \\ Viviane Muller Prado****
}

\section{Resumo}

$\mathrm{Na}$ esfera internacional, governamentais, agentes estatais e reguladores se encontram para discutir e aprovar padrões e recomendações sobre como regular o mercado de valores mobiliários. Esses produtos regulatórios não integram o rol das normas reconhecidas pelo direito internacional público, diferentemente daquelas dos tratados e dos costumes internacionais. Embora formalmente não obrigatórios, pelo fato de condicionarem o comportamento dos reguladores brasileiros e por influenciarem a regulação nacional, tais produtos não estão livres de mecanismos de controle. O objetivo deste trabalho é identificar esses mecanismos no processo de internalização de produtos regulatórios transnacionais. Para tanto, parte-se do estudo do caso de implementação das recomendações e diretrizes formuladas pela International Organization of Securities Commissions - IOSCO por parte da Comissão de Valores Mobiliários - CVM, entidade com competência de regular o mercado de valores mobiliários brasileiro. O caso revela que o Brasil participa de foros transnacionais e, também, internaliza os seus produtos. A entrada desses produtos regulatórios ocorre com o exercício do poder normativo da CVM, que se utiliza dos seus mecanismos de controle (accountability) usuais na sua produção normativa, tais como audiências públicas, justificativas e relatórios. A principal contribuição do trabalho é anunciar elementos concretos que permitem avançar na reflexão sobre a complexidade do fenômeno da regulação produzida nos espaços transnacionais. Ademais, levanta a dúvida quanto à transferência do poder normativo do plano doméstico para as redes transnacionais e sua legitimidade.

Palavras-chave: Regulação transnacional. Direito internacional. Accountability. Mercado de capitais. IOSCO. CVM.

\section{Abstract}

*** Professora de Direito do Mackenzie. Pós-douradanda na FGV Direito SP. Doutora em Relações Internacionais pela USP. Email: viviane.prado@fgv.br

**** Professora de Direito dos Negócios da FGV Direito SP. Coordenadora do Núcleo de Estudos de Mercados e Investimentos da FGV Direito SP. Doutora em Direito pela USP.

Email: nora.rachman@gmail.com

** Professor de Direito Internacional e Coorvolvimento da FGV Direito SP. Doutor em Direito Internacional pela USP. Email: salem. nasser@fgv.br
In the international arena, governmental authorities, state agents and regulators get together to establish standards and recommendations on the regulation of securities markets. Such regulatory products are not part of 
the recognized norms of public international law, unlike those contained in treaties and customary law. Despite being non-binding, because they help determining the behavior of the Brazilian regulator and because they influence the content of domestic regulations, such products are not exempt from accountability mechanisms. The aim of this paper is to identify these mechanisms in the process of internalization of transnational regulatory products. It does so by studying the implementation process for the recommendations and guidelines set by the International Organization of Securities Commissions - IOSCO that is used by Comissão de Valores Mobiliários - CVM, the Brazilian body responsible for regulating the domestic securities market. The case study reveals that Brazil takes part in transnational regulatory fora and also internalizes its outputs. The insertion of these regulatory outputs in Brazilian territory occurs through the exercise by CVM o its given regulatory powers. As it operates this insertion, CVM makes use of its usual accountability instruments such as public consultations, justifications and reports. The paper's main contribution is to offer some concrete elements that can be useful in assessing the complexity of transnational regulation and its internalization processes. It poses, finally the doubt concerning the effect of transferring parts of the normative powers from the domestic, state, arena towards the transnational one for the legitimacy of the regulatory outputs.

Keywords: Transnational regulation. International law. Accountability. Securities market. IOSCO. CVM.

\section{INTRODUÇÃO}

A produção normativa na esfera internacional, se algum dia foi tarefa exclusiva dos Estados e do direito internacional público, há muito já não o é. Atenção, no entanto. Não está dito que a resultante dessa produção normativa seja direito. Não está dito que todas as normas são normas jurídicas.

O direito internacional público concorre crescentemente com fenômenos normativos ou regulatórios que recebem denominações variadas e são objeto de estudos diversos que lhes dão recortes diferentes. Go- vernança, muitas vezes dita global, ${ }^{1}$ soft law, ${ }^{2}$ regulação transnacional, ${ }^{3}$ ação administrativa global, ${ }^{4}$ direito internacional informal, ${ }^{5}$ são alguns dos nomes que conhece essa produção normativa que concorre ou coabita com o direito internacional.

Os autores dos vários produtos regulatórios ${ }^{6}$ que não são parte do direito internacional público, mas que são criados e operam internacionalmente, são igualmente variados: organizações internacionais, Estados ou órgãos governamentais, entes privados, agindo conjuntamente ou não.

Uma pergunta fundamental, que deve estar presente, ainda que não fique necessariamente resolvida, em qualquer investigação acerca dessa ação regulatória na esfera internacional, diz respeito à natureza jurídica ou não dos seus produtos, das suas normas. É a questão das fronteiras entre o direito e o não direito.

O modo mais pragmático de lidar com essa questão pede um descolamento de visões essencialistas da na-

1 Uma referência entre tantas outras: SLAUGHTER, Anne-Marie. Everyday global governance. Research Library Core, v. 132, n. 1, p. 83-90, 2003.

2 Consultar, por exemplo: NASSER, Salem H. Fontes e normas do direito internacional: um estudo sobre a soft law. 2. ed. São Paulo: Atlas, 2006.

3 Consultar: especialmente no que respeita à regulação privada transnacional, CAFAGGI, Fabrizio. The architecture of transnational private regulation: EUI working papers, Law 2011/12. Italy: Department of Law. Disponível em: <http://cadmus.eui.eu/ handle/1814/18256>. Acesso: out. 2015. e New Foundation of Transnational Private Regulation, EUI Working Papers, Robert Schuman Center for Advanced Studies. Private Regulation Series - 04. Disponível em <http://cadmus.eui.eu/bitstream/handle/1814/15284/RSCAS_2010_53.pdf?sequence=1> Sobre diferentes formas de produção normativa privada, na perspectiva do direito internacional, ver ainda: ELIAS, Fernando Lopes Ferraz. A internacionalização do direito a partir de diferentes fenômenos privados de construção normativa. Revista de Direito Internacional, Brasilia, v. 11, n. 1, p. 1136-1163, 2013.

4 Consultar: < http://www.iilj.org/gal> e especialmente KINGSBURY, B.; KRISCH, S.; STEWART, R. The Emergence of global administrative law: Law and Contemporary Problems, v. 68, p. 15-61, 2005.

5 Consultar: $<$ http://www.hiil.org/project/informal-international-law-making-and-accountability $>$ e, especialmente NASSER, S. H.; MACHADO, A. M. F. Informal International lawmaking and accountability in Brazil. In: BERNAN, A. et al. (Ed). Informal international lawmaking: case studies: the Hague: Torkel Opsahl Academic EPublisher, 2012. p.141 - 178.

6 Para fins deste artigo, a expressão produtos regulatórios é entendida como o resultado de produção normativa ou regulatória. Incluem-se nessa categoria a formulação e/ou consolidação de recomendações, padrões, modelos, princípios, diretrizes, relatórios técnicos. 
tureza do jurídico e uma redução de seu escopo à identificação do pertencimento das normas a uma ordem jurídica dada. A juridicidade das normas, a sua validade, só pode ser dada por um sistema jurídico de que a norma faça parte.

O direito internacional público reconhece a validade das normas que surgem pela via de suas duas fontes: tratados e costumes? ${ }^{7}$. Como se está falando, essencialmente, de produtos normativos que não estão contidos em tratados internacionais firmados entre Estados ou organizações internacionais e que não decorrem da prática generalizada dos Estados à qual se conjuga a convicção da juridicidade dessa prática, está claro que esses produtos não fazem parte do direito internacional público.

Note-se, no entanto, por um lado, que o direito internacional público faz parte necessariamente de qualquer processo que se queira chamar de governança global, uma governança, uma ordenação do mundo que se faz pelo direito e pelo não direito. Por outro lado, é preciso lembrar, também, que uma parte da ação administrativa operada por organizações internacionais, especificamente, mas por outros atores também, se faz em decorrência de competências ou funções definidas pelo direito internacional.

Essa produção regulatória que não pertence à categoria de normas juridicamente válidas perante o direito internacional público deve, ainda assim, suscitar um grande interesse por parte dos juristas. E isso porque, apesar de não jurídica, a regulação, muitas vezes dotada de enorme efetividade, diz respeito a questões que são de interesse público. Além do impacto que essas normas representam em termos de previsibilidade do conteúdo normativo para os agentes alvo da regulação, chama a atenção que a porta de entrada de uma norma no ambiente doméstico decorra de discussões travadas num ambiente internacional não-formal. Esse é o caso da regulação produzida pela International Organization of Securities Commissions - IOSCO, uma organização que congrega autoridades reguladoras dos mercados de capitais mais relevantes e cuja função é estabelecer padrões a serem seguidos em todos esses mercados.

7 Não se ignora o debate sobre a composição mais ampla ou mais restrita do rol das fontes do direito internacional público e sobre papel do artigo 38 do Estatuto da Corte Internacional de Justiça. Sobre essa discussão, ver NASSER, Salem H. Fontes e normas do direito internacional: um estudo sobre a soft law. 2. ed. São Paulo: Atlas, 2006. p. 49-72.
Porque a regulação lida com questões de interesse público, mas também porque muitas vezes aquilo que é produzido na esfera internacional virá a constituir o instrumental que efetivamente regulará determinado setor da vida interna, nacional, o tema é obrigatório para juristas e para todos os que lidam com políticas públicas. Esse é igualmente o caso das recomendações e diretrizes formuladas pela IOSCO em relação ao conteúdo cuja competência regulatória é exercida no Brasil pela Comissão de Valores Mobiliários - CVM.

Há, portanto, produção na esfera internacional, ou transnacional para quem o preferir, pela IOSCO, por meio de padrões sobre como regular o mercado de valores mobiliários. Há, ainda, a incorporação, a internalização ou a implementação dessa regulação na esfera do doméstico, do nacional, pela CVM, com competência de regular o mercado de valores mobiliários brasileiro.

A internalização ou incorporação ao direito interno das normas acordadas entre Estados nos tratados internacionais passa, em princípio, por mecanismos de legitimação contidos nas normas do ordenamento jurídico nacional que organizam as competências dos poderes para celebrar tratados, aprovar a sua celebração e seus conteúdos, dar-lhes publicidade etc. Antes disso, no contexto do direito internacional público, as normas atinentes aos tratados asseguram, também, em princípio, a sua legitimidade ao garantirem a primazia da vontade soberana estatal.

Já em relação às normas produzidas fora das fontes do direito internacional público, concernentes a temas de interesse público e destinadas a surtirem efeitos ou serem aplicadas nas sociedades domésticas, cabe se interrogar sobre as condições de legitimação e mecanismos de controle (accountability) dos processos de formação normativa, no plano internacional ou transnacional, e dos processos de internalização ou implementação nacional.

Essa interrogação é o norte que orienta este trabalho que se ocupará especificamente da participação da CVM em foros internacionais, enquanto autoridade nacional reguladora dos mercados e da implementação nacional das diretrizes produzidas pela IOSCO no mercado brasileiro.

Após uma breve discussão sobre os mecanismos de internalização no Brasil das normas convencionais internacionais e sobre a internalização dos instrumentos normativos que nos ocupam aqui, é apresentado o 
estudo do caso da implementação, pela CVM, dos produtos regulatórios da IOSCO. Nesse caminho, estão organizadas informações sobre a participação da agência reguladora do mercado de valores mobiliários brasileira naquele foro transnacional, bem como relatos que indicam se e como a CVM internaliza os produtos da regulação transnacional da IOSCO. O objetivo do estudo de caso é identificar os mecanismos de accountability existentes para a implementação.

\section{ReGRAS BRASILEIRAS SOBRE CONCLUSÃO DE ACORDOS INTERNACIONAIS E SOBRE A INCORPORAÇÃO DO DIREITO INTERNACIONAL PÚBLICO}

\subsection{Direito internacional}

Como se sabe, de acordo com o artigo 84, III da Constituição brasileira, o presidente da República é a autoridade competente para celebrar tratados internacionais, ad referendum do Congresso Nacional. Isto significa que a iniciativa e também a decisão final sobre expressar ou não o consentimento do Brasil em vincular-se por um tratado ${ }^{8}$ está, nas mãos daqueles membros do poder executivo que, de acordo com o direito internacional, tem o poder de obrigar o Estado perante outros Estados ou perante as Organizações Internacionais. ${ }^{9}$

Tal decisão final do Presidente depende de uma autorização do Congresso Nacional, quando possa representar um ônus para o tesouro nacional, nos termos do artigo 49, I da Constituição Federal. Parece que essa última condição referente ao impacto para o tesouro teria sido incluída no texto constitucional de 1988 para assegurar que acordos, por exemplo, com o Fundo Monetário Internacional, como os que o Brasil celebrou em anos anteriores, sem aprovação legislativa, teriam que passar pelo escrutínio de deputados e senadores. ${ }^{10}$

8 Aqui a palavra é usada em seu sentido genérico: um acordo submetido ao direito internacional e obrigatório para as partes que são ou Estados, ou Organizações Internacionais.

9 Estes membros do executivo são: o Ministro das Relações Exteriores e os chefes de missões diplomáticas. É claro que o Presidente pode também autorizar pessoas a negociarem e celebrarem tratados específicos e expressarem o consentimento do Brasil em se ver vinculado por eles.

10 Alguns consideram que, na verdade, a iniciativa que visaria a
A interpretação de consenso, no entanto, que combina os dois artigos constitucionais, diz que todos os acordos internacionais e todos os tratados deveriam passar pelo duplo processo, em que o Congresso $\mathrm{Na}$ cional deve aprovar todos os tratados, requeiram estes ratificação ou não, quer antes, quer depois que o processo de negociação tenha sido concluído.

Uma vez que o Brasil passa a integrar um acordo internacional, este último deveria ser incorporado tal qual previsto no sistema jurídico nacional brasileiro. Os tribunais brasileiros têm decidido consistentemente que, para que aconteça a incorporação de um tratado em nosso sistema, é necessário que o Presidente emita um decreto de promulgação que dê publicidade ao tratado e à sua entrada em vigor. De acordo com jurisprudência assentada, a ausência do decreto ou a sua emissão tardia poderia levar à situação em que o tratado pelo qual o Brasil está obrigado internacionalmente será considerado como não estando em vigor na ordem doméstica. É claro que, a rigor, o mesmo pode acontecer quando o Brasil expressar seu consentimento com se obrigar internacionalmente, sem ter para isso obtido a aprovação do Congresso.

Apesar da aceitação geral do princípio de que todos os acordos deveriam passar pelo processo de aprovação, a verdade é que isto não acontece de fato com muitos deles, ainda mais quando são tratados de acordo com o direito internacional. Alguns são celebrados pela Presidência da República ou pelo Ministério das Relações Exteriores, e outros por outros ministérios ou agências.

A primeira e mais superficial explicação para isso é o caráter impraticável, em termos de tempo e procedimentos, de fazer passar cada acordo pela aprovação do Congresso. O momento crítico viria quando tribunais brasileiros tenham que decidir se qualquer desses acordos legalmente vinculantes, cujo descumprimento levaria à responsabilização internacional do Brasil, são, ainda assim, parte integrante do direito doméstico brasileiro e se podem produzir efeitos jurídicos no Brasil.

De todo modo, muitos desses acordos que não passam pelos procedimentos de aprovação no Congresso seriam o que se tende a chamar de acordos administrativos, ou seja, a substância do que está ali negociado e acordado entra no universo dos poderes regulatórios

um maior rigor pode também ser, paradoxalmente, lida como uma limitação dos tipos de acordos que teriam que obter a aprovação do Congresso. 
detém o agente brasileiro ou o universo de seu poder para a ação discricionária.

No que se refere ao direito internacional costumeiro, apenas umas poucas palavras se fazem necessárias. Os tribunais brasileiros podem aplicar - e aplicam de fato - princípios reconhecidos do direito internacional que, por não estarem incorporados em acordos ou tratados internacionais, não passam por qualquer processo de internalização. Eles são, no entanto, reconhecidos em princípio como integrando o ordenamento nacional. Quais princípios são assim reconhecidos é algo que, pela natureza mesma do costume, só se poderá decidir diante de cada caso concreto.

\subsection{Regulação transnacional}

Esse quadro geral dos modos pelos quais o direito internacional é incorporado no Brasil não permite identificar quaisquer respostas claras para a incorporação dos produtos regulatórios internacionais ou transnacionais. Isso decorre do fato de que são características fundamentais desse tipo de regulação o seu caráter não obrigatório e o seu surgimento com base em mecanismos ou processos que não são as fontes do direito internacional público.

Como, justamente, não surgem a partir das fontes do direito internacional, esses produtos não são reconhecidos por esse ordenamento jurídico como sendo parte integrante de seu corpus normativo. Porque não são obrigatórios, podem ocorrer desencontros entre o comportamento prescrito e o comportamento efetivo dos Estados. Isto não dá ensejo à sua responsabilização internacional. Da mesma forma, não ficam sujeitos ao mesmo processo de incorporação dos tratados internacionais no Brasil.

É claro que alguém poderia pensar acordos a que chegam, na esfera internacional, autoridades governamentais, agentes estatais, reguladores autorizados, como sendo acordos celebrados pelo Estado brasileiro. $\mathrm{E}$, poderia-se pensar que, ainda que formalmente não obrigatórios, por condicionarem o comportamento dos reguladores brasileiros e por influenciarem a regulação nacional, não poderiam estar de todo livres de mecanismos de controle a que se submeteriam os tratados internacionais. Esse é um problema relevante para a discussão em termos de mecanismos de controle (accountability) da regulação transnacional.
Um aspecto central do tema da accountability é os formuladores dessa regulação transnacional exercem uma espécie de autoridade pública, na medida em que, efetivamente, determinam ou condicionam o comportamento em matérias de interesse público. Os atores potencialmente afetados são Estados ou entes não estatais.

Quanto à determinação do comportamento estatal, pelo fato de a regulação transnacional não ter qualquer caráter obrigatório, a sua aceitação é consequência de alguma outra consideração de prudência, interesse, falta de opções, etc. ${ }^{11}$ No que diz respeito aos atores não estatais, eles podem participar de uma instituição ou rede de produção regulatória e, ainda, aceitar implementar alguns ou todos os produtos regulatórios ali gerados ${ }^{12}$.

Antes de tudo, é preciso verificar se o Estado é parte do acordo que deu origem à instituição ou à rede transnacional ou dos acordos que estabeleceram, modificaram ou regulam o seu funcionamento. Também é necessário identificar se há um pacto no sentido de incorporar ou implementar os produtos da instituição transnacional e verificar, finalmente, se o produto ou os produtos são eles mesmos acordos.

A questão que se coloca é se há necessidade de um sistema de controle ou aprovação de acordos sempre que os produtos regulatórios vinculem o Estado, ainda que não sob o ponto de vista jurídico. Isso ocorreria, por exemplo, no caso da participação do Estado no documento de constituição ou de adesão a uma rede transnacional, ou ainda, sempre que o Estado implementar, assinar e obrigar-se por meio de um acordo específico. ${ }^{13}$

A questão é mais sensível quando o Estado entende que está comprometido com o processo de implementação de produtos regulatórios das redes transnacionais. Neste aspecto, se algum controle existe, levará em conta a substância do que foi ou será implementado. Mas a substância, a regulação do setor, é implementada pelo regulador, em princípio, nos termos do seu mandato legal e poderes delegados em lei. Esse controle, portanto, diz respeito à atividade regulatória no plano doméstico e não tem necessariamente relação com o fato de que a origem da substância da regulação é um acordo internacional não obrigatório.

11 Eventualmente os Estados podem adotar os padrões por outras razões, sejam eles membros ou não da rede transnacional.

12 A respeito, vide exemplos das entidades autorreguladoras brasileiras que integram a IOSCO, item 3.3.2.c.

13 Este último é o caso do documento da IOSCO referido como MMOU, referido no item 3.1 . 
Em outras palavras, há dois elementos a serem levados em conta. Primeiro, o conteúdo das medidas ou dos regulamentos a serem internalizados. Segundo, o fato de que tal conteúdo tem sua origem numa instituição ou numa rede internacional. Tais elementos podem ser considerados como integrantes de numa única questão fundamental: por que razão uma medida regulatória específica está sendo adotada ou implementada?

\section{ESTUDO DE CASO: IMPLEMENTAÇÃO DOS PRODUTOS REGULATÓRIOS DA IOSCO PELA CVM}

\subsection{IOSCO, sua atividade e seus documentos}

Os mercados financeiros e de capitais são conhecidos por terem agentes econômicos atuando globalmente, seja na posição de instituições que oferecem produtos ou serviços financeiros, seja na figura dos investidores que atuam em vários mercados e também daqueles que captam recursos. A crise financeira de 2008 evidenciou, de forma aguda, que problemas em alguns mercados contaminam diretamente outros. Mostrou, ainda, que escolhas regulatórias mais permissivas de alguns sistemas jurídicos podem ter consequências em outros, ainda que com regulação mais robusta. Revelou o desafio de compreender como os produtos regulatórios internacionais podem configurar-se como instrumentos para evitar novas crises sistêmicas, incluindo a reflexão sobre os fenômenos das convergências regulatórias informais, a fragmentação regulatória e descentralização regulatória cooperativa. ${ }^{14}$

Constatou-se, também, que produtos do mercado bancário deveriam ser fiscalizados e regulados em conjunto com outros ofertados nos mercados de valores mobiliários e de seguros. A segregação da regulação por temas com competências alocadas em várias agências reguladoras nacionais e em redes internacionais mostrou-se insatisfatória como desenho institucional.

Com isso, a rede de instituições internacionais for-

14 HELLEINER, Eric; PAGLIARI Stefano. The end of an era in international financial regulation? a postcrisis research agenda. International Organization 65, 2011, p. 170. Disponível em: <http:// www.stefanopagliari.net/helleiner_pagliari_-_the.pdf $>$ Acesso em: 12 out. 2015. mada por reguladores nacionais com a tarefa de indicar linhas gerais para a regulação dos mercados bancários, de valores mobiliários, seguros e o sistema contábil ganhou atenção tanto do mercado quando de acadêmi$\cos .^{15}$ Nessa rede se insere a IOSCO, cujo foco na definição de standards está voltado para a regulação dos mercados de capitais.

A IOSCO foi criada em 1983, mas não pela assinatura de tratado internacional ou acordo entre Estados e, por isso, não pode ser considerada uma verdadeira organização internacional. ${ }^{16}$ Apesar disso, congrega atualmente mais de $95 \%$ do mercado mundial de valores mobiliários, contando com reguladores de 115 países como membros. ${ }^{17}$

Conforme declarado no seu estatuto, seus objetivos são:

(1) cooperar, implementar e promover os padrões internacionalmente reconhecidos de regulação, supervisão e enforcement com o fim de proteger investidor, manter os mercados justos, eficientes e transparentes, afastando o risco sistêmico;

(2) aperfeiçoar a proteção dos investidores e promover a sua confiança na integridade dos mercados de valores mobiliários, mediante troca de informações e cooperação na atividade de enforcement contra condutas ilícitas e na supervisão de mercados e dos intermediários; e

(3) troca de informações em nível global e regional das suas respectivas experiências para ajudar o desenvolvimento de mercado, aperfeiçoar as estruturas de mercado e implementar de regulação apropriada. ${ }^{18}$

15 BRUMMER, Chris. Soft law and the global financial system: rule making in the 21 st century. Cambridge: Cambridge University Press, 2012. HELLEINER, Eric; PAGLIARI Stefano; ZIMMERMAN, H (Ed.). Global finance in crisis: the politics of international regulatory change. London: Routledge, 2010. BÜTHE, Tim; MATTLI, Walter. The new global rulers: the privatization of regulation in the world econ:omy. Princeton: Princeton University Press, 2011. ZARING, David. Finding legal principle in global financial regulation. Journal of International Law, Virginia, v.53, n.3, p. 683-721.

16 VERDIER, Pierre-Hugues. Transnational regulatory network and their limits. The Yale Journal of International Law, v. 34, n. 1, p. 113-172, 2009.

17 Os seus membros são divididos em três categorias: ordinários (reguladores: comissões de valores mobiliários), associados (reguladores supranacionais, subnacionais, organizações intergovernamentais ou outras instituições consideradas formuladoras de padrões ou standard-setters), afiliados (entidades autorreguladoras, bolsas, instituições internacionais). Disponível em: http://www. iosco.org/about/?subsection=about_iosco. Acesso em: Outubro de 2015.

18 INTERNATIONAL ORGANIZATION OF SECURITIES COMMISSIONS. Estatuto social. Disponível em: <http://www. 
Sua atividade, todavia, não se é exercida necessariamente de forma isolada, tendo forte atuação conjunta com outras instituições em fóruns específicos, tais como, o Joint Forum, criado em 1996. A IOSCO faz parte deste foro junto com o BCBS - Basel Committee on Banking Supervision, e LAIS - International Association of Insurance Supervisors. A função desta conjugação de esforços é tratar de questões comuns aos mercados bancário, de valores mobiliários e de seguros, incluindo a regulação dos conglomerados financeiros. ${ }^{19}$

Outra atuação conjunta se dá no Financial Stability Forum (FSF), criado em 1999, juntando instituições consideradas como standards setters (Basel Committee on Banking Supervision - BCBS, International Association of Insurance Supervisors - IAIS, IOSCO, International Accounting Standards Board - IASB e Committee on Payment and Settlement Systems - CPSS), organizações internacionais (Fundo Monetário Internacional - FMI, Banco Mundial, Organization for Economic Co-operation and Development - OCED, Bank for International Settlements - BIS, Banco Central Europeu - ECB, Committee on Global Financial System), assim como autoridades financeiras nacionais. Apesar desse foro comum, a crise de 2008 evidenciou que a fragmentação permaneceu sendo um desafio. Após 2008, o G20 renomeou esse foro como o Financial Stability Board (FSB) e conferiu-lhe a com a missão de coordenar e supervisionar os trabalhos de outas instituições consideradas standard setters. Além disso, os comitês técnicos da IOSCO - e também do Basel Committee, expandiram os seus membros para os mercados emergentes, convidando o Brasil - bem como China e Índia - para se juntarem como membros destes foros. ${ }^{20}$

A forma de atuação da IOSCO e divulgação de seus entendimentos se dá a partir dos seus três principais documentos:

(1) IOSCO Objectives and Principles of Securities Regulation, criado em 1998, com adaptações feitas em 2003, 2008 e 2010. Este documento traz as linhas mestras para aperfeiçoar a qualidade da regulação do mercado de valores mobiliários. Foi endossado pelo G20 e pelo FSB, em razão da percepção de que os princípios nele enunciados são relevantes para regulação, monitoramento de

iosco.org/library/by_laws/pdf/IOSCO-By-Laws-Section-1-English.pdf>. Acesso em: 12 out. 2015.

19 INTERNATIONAL ORGANIZATION OF SECURITIES COMMISSIONS. Joint Forum. Disponível em: < https://www.iosco. org/about/?subsection=joint_forum >. > Acesso em: 12 out. 2015. 20 VERDIER, Pierre-Hugues. The political economy of international financial regulation. Indiana Law Journal, v. 88, p. 1461, 2013. mercado e enforcement. ${ }^{21}$

(2) IOSCO Principles Assessment Methodology, que serve para a auto avaliação das jurisdições e também é utilizada pelos Financial Sector Assessment Programs (FSAPs) do FMI e do Banco Mundial para avaliação das várias jurisdições. ${ }^{22}$

(3) Multilateral Memorandum of Understanding Concerning consultation and cooperation and the Exchange of information (IOSCO MMoU). Esse documento foi criado para facilitar o enforcement transfronteiriço (cross-border) e a troca de informações entre reguladores nacionais. Apesar de não ser vinculante sob o ponto de vista jurídico, o IOSCO MMoU é o principal instrumento internacional de cooperação entre as comissões de valores mobiliários nacionais. ${ }^{23}$ Atualmente, são 105 membros da IOSCO que assinaram o MMoU, sendo que 18 membros se comprometeram a buscar autorização na estrutura burocrática dos seus respectivos países para ter poderes de aderir a tal documento. ${ }^{24}$

Há, ainda, os relatórios temáticos produzidos pelos diversos da entidade ${ }^{25}$, que também têm servido como inspiração e suporte para os reguladores locais, com disponibilização e informações e modelos regulatórios.

É importante notar que o esforço da conjugação de reguladores não garante a harmonização regulatória dos mercados de valores mobiliários nacionais, pois não há mecanismos de enforcement do que está previsto nesses

21 INTERNATIONAL ORGANIZATION OF SECURITIES COMMISSIONS. Objectives and principles of securities regulation. Disponível em: <http://www.iosco.org/library/pubdocs/pdf/ IOSCOPD82.pdf $>$. Acesso em: 12 out. 2015. Conforme VERDIER, os Princípios e Objetivos, além de auxiliar os esforços domésticos para melhorar a regulação de mercado, vem sendo citados em pronunciamentos sobre o mercado num nível mais generalista, evitando-se, assim, temas potencialmente controversos (VERDIER, Pierre-Hugues. Transnational regulatory network and their limits. The Yale Journal of International Law, v. 34, n. 1, p. 113-172, 2009.)

22 INTERNATIONAL ORGANIZATION OF SECURITIES COMMISSIONS. Principles assesment methodology. Disponível em: <http://www.iosco.org/library/pubdocs/pdf/IOSCOPD359. pdf $>$. Acesso em: 12 out. 2015.

23 Verdier considera este acordo cooperativo como uma história de sucesso em matéria de regulação financeira internacional, por conseguir coordenar as ações dos reguladores domésticos no fechamento de lacunas em matéria de enforcement e supervisão de mercado. Vide VERDIER, Pierre-Hugues. The political economy of international financial regulation. Indiana Law Journal, v. 88, p. 1461, 2013. 24 INTERNATIONAL ORGANIZATION OF SECURITIES COMMISSIONS. Principles assesment methodology. Disponível em: <http://www.iosco.org/library/pubdocs/pdf/IOSCOPD359. pdf $>$. Acesso em:12 out. 2015.

25 Além do Comitê Técnico, mencionem-se os Comitês de Mercados Emergentes, os Comitês Regionais e os Comitês Consultivos da IOSCO. Os Relatórios são produzidos em bases temáticas, mas sua aprovação usualmente passa pelo Comitê Técnico. 
documentos, nem obrigatoriedade de adoção das recomendações da IOSCO pelos seus membros. Esse ponto está bastante claro no próprio estatuto de IOSCO. ${ }^{26}$

\subsection{CVM em foros internacionais e sua participação na IOSCO}

A CVM participa de vários foros que formam a rede internacional e trazem as diretrizes para a regulação dos mercados de capitais e financeiros. Ela é membro da IOSCO, do Financial Stability Board - FSB, da OCDE, especificamente no Corporate Governance Committee, da Fundação IFRS - International Financial Reporting Standards (Monitoring Board), conjunto de pronunciamentos contábeis internacionais edo GAFI/FATF - Grupo de Ação Financeira contra lavagem de dinheiro e o financiamento ao terrorismo. ${ }^{27}$

$\mathrm{Na}$ IOSCO, a CVM é membro fundadora desde $1983^{28}$, juntamente a outras agências reguladoras do mercado de capitais da América do Norte e do Sul. Durante os anos que seguiram sua fundação até 2008, quando eclodiu a crise financeira internacional, a CVM atuou em diversos comitês, foros de discussão e grupos de trabalho da $\mathrm{IOSCO}^{29}$. Em 2011, além da participação dos Comitês Técnicos, Executivo e de Mercados Emergentes e dos sete comitês permanentes da IOSCO, a CVM foi eleita para presidir o Comitê Executivo. ${ }^{30}$ Este

26 Redação original: "83. The standard setting and related activities of the Organization (including any decisions reached or documents issued) are not binding and do not give rise to any legal rights or obligations. Members participate in the Organization in accordance with their respective legal and policy frameworks, which may not be modified or superseded by these By-laws or any decision of the Organization. Member participation in any of the Organization's standard setting or projects, reports, or other activities should not be viewed as an expression of a judgment by any member regarding their current or future regulatory proposals, rulemaking, or standards implementation work or limit their choices regarding proposed or final versions of their rules or standards." Disponível em: <http://www.iosco.org/library/by_laws/pdf/IOSCO-By-LawsSection-1-English.pdf>. Acesso em: 12 out. 2015.

27 COMISSÃO DE VALORES MOBILIÁRIOS. Relatório anual da CVM de 2014. p. 114. Disponível em <http://www.cvm.gov. $\mathrm{br} /$ export/sites/cvm/publicacao/relatorio_anual/anexos/Relatorio_Anual_2014.pdf>. Acesso em: 12 out. 2015.

28 Sobre esta informação. Disponível em: <http://www.cvm. gov.br/menu/internacional/organizacoes/iosco.html>. Acesso em: ago. 2015.

29 Para uma síntese da atividade da CVM nos anos de 2005, 2006 e 2007, consultar os respectivos Relatórios Anuais da instituição. Disponíveis em: <http://www.cvm.gov.br/publicacao/relatorio_ anual.html>. Acesso em: 14 out. 2015.

30 Era composto por 19 membros, entre eles, os presidentes dos era, à época, o órgão colegiado responsável pelas decisões políticas e pelas medidas necessárias para atingir os objetivos da IOSCO. ${ }^{31}$

Em 2012 houve modificação na estrutura de governança da IOSCO, que consistiu na união do Comitê Executivo e do Comitê Técnico para formar o novo Conselho ("Board") da IOSCO. Atualmente, esse órgão é composto por 32 membros, entre eles um representante da CVM. ${ }^{32}$ Em 2013, o Presidente da CVM foi eleito pelo Conselho da IOSCO para coliderar os trabalhos de um comitê recém-criado de Política Regulatória, com o objetivo de desenvolver iniciativas e recomendações na área de proteção e educação dos investidores de varejo. ${ }^{33}$

Em 2014, o representante da CVM foi eleito Vice-Presidente do Comitê de Crescimento e de Mercados Emergentes ("Growth \& Emerging Markets Committee"). ${ }^{34}$ De acordo com o seu relatório anual de 2014, a CVM no momento atua nos seguintes Comitês e Forças-tarefas: Regulação dos intermediários de mercado, Comitê de administração de investimentos, Comitê de enforcement e troca de informações, comitê de riscos emergentes, e comitê de investidor de varejo. ${ }^{35}$

Não é possível afirmar como se dá a participação da CVM nas instâncias de discussão e deliberação da IOS$\mathrm{CO}$, até porque o processo de tomada de decisão não é

comitês técnico, de mercados emergentes, e os presidentes das autoridades reguladoras do Brasil, China, Índia, Estados Unidos e de países da União Europeia. Disponível em: < http://www.cvm.gov. br/export/sites/cvm/publicacao/relatorio_anual/anexos/Relatorio_Anual_2011.pdf>. Acesso em: 12 out. 2015.

31 INTERNATIONAL ORGANIZATION OF SECURITIES COMMISSIONS. Relatório Anual da IOSCO 2011. P.4-10. Disponível em: <https://www.iosco.org/annual_reports/2011/>. Acesso em: out. 2015.

32 INTERNATIONAL ORGANIZATION OF SECURITIES COMMISSIONS. Relatório Anual da IOSCO 2011. p 51. Disponível em: < https://www.iosco.org/annual_reports/2011/>. Acesso em: 27 ago. 2015. "IOSCO Board". Disponível em: <https://www. iosco.org/about/?subsection=display_committee\&cmtid=11>. Acesso em: 12 out. 2015.

33 COMISSÃO DE VALORES MOBILIÁRIOS. Relatório anual de 2013. Disponível em: <http://www.cvm.gov.br/export/sites/ cvm/publicacao/relatorio_anual/anexos/Relatorio_Anual_2013. pdf $>$. Acesso em: 12 out. 2015.

34 COMISSÃO DE VALORES MOBILIÁRIOS. Relatório anual da CVM de 2014. p. 116. Disponível em <http://www.cvm.gov. $\mathrm{br} /$ export/sites/cvm/publicacao/relatorio_anual/anexos/Relatorio_Anual_2014.pdf>. Acesso em: 12 out. 2015.

35 COMISSÃO DE VALORES MOBILIÁRIOS. Relatório anual da CVM de 2014. p. 116-121. Disponível em <http://www.cvm. gov.br/export/sites/cvm/publicacao/relatorio_anual/anexos/Relatorio_Anual_2014.pdf>. Acesso em: 12 out. 2015. 
transparente e nem aberto a escrutínio púbico. Entretanto, verifica-se que a CVM se encontra bastante representada nas atividades da IOSCO, contribuindo com a evolução da regulação brasileira e com a apropriação da experiência de outros reguladores e mercados.

\subsection{Mecanismos de controle na atividade normativa da cvm na internalização das regras da iosco}

\subsubsection{Poder normativo da CVM, processo de regu- lação e audiências públicas}

A CVM é uma autarquia em regime especial, criada pela Lei 6.385/1976. Está ligada ao Ministério da Fazenda e divide sua competência com o Conselho Monetário Nacional - CMN, órgão superior da regulação do Sistema Financeiro Nacional. ${ }^{36}$ É competente para regular o mercado de ações, debêntures, bônus de subscrição, certificados de depósitos de valores mobiliários, fundos de investimentos e clubes de investimentos, notas comerciais, contratos futuros, opções, derivativos e contratos coletivos de investimentos, conforme art. $2^{\circ}$ da Lei 6.385/1976.

Em seu mandato legal da CVM, está previsto estimular a formação de poupança e aplicações em valores mobiliários, promover a expansão e funcionamento eficiente e regular dos mercados sob sua competência; proteger os investidores em valores mobiliários contra emissões irregulares, atos ilegais de administradores e controladores de companhias abertas, bem como uso de informações privilegiadas; evitar ou coibir modalidades dos ilícitos do mercado secundário; assegurar o acesso do público à informação (art. 4º da Lei 6.385/1976).

Para cumprir o seu mandato legal, exerce atividades de criação de normas, supervisão dos mercados e punição dos ilícitos praticados nos mercados sob sua competência (arts. $8^{\circ}$ e $9^{\circ}$ da Lei 6.385/1976). Para fins deste estudo, que pretende analisar o processo de internalização de regras da IOSCO, é relevante conhecer o processo normativo da CVM.

A própria lei que a criou delegou o poder normativo para a CVM para as seguintes matérias: (i) condições e procedimentos para a obtenção de autorização

36 Sobre competência do CMN e divisão com a CVM na Lei n. 6.385/76 e Lei n. 4595/64. ou registros necessários para a distribuição de valores mobiliários, compra de valores mobiliários para fins de revende-los, corretagem e mediação de operações com valores mobiliários, compensação e liquidação de operações com valores mobiliários, (ii) requisitos de idoneidade, habilitação técnica e capacidade financeira dos administradores dos emissores e outras pessoas que atuam no mercado de valores mobiliários, (iii) constituição e extinção das instituições organizadoras dos mercados organizados e de Bolsa, (iv) exercício do poder disciplinar das Bolsas e mercados organizados e entidades de compensação e liquidação em operações de valores mobiliários; (iv) sociedades corretoras, (v) condições para realização de operações a termo; (vi) definir as operações autorizadas a serem realizadas em bolsa e em mercado organizado, elementos dos ilícitos de mercado.

O limite dos seus poderes normativos, além da abrangência temática, está no princípio da legalidade previsto na Constituição Federal, no seu art. 5 ${ }^{\circ}$, inciso II, segundo o qual "ninguém será obrigado a fazer ou deixar de fazer alguma coisa senão em virtude de lei". Para que a CVM exerça regularmente e de forma lícita a sua atividade de criação de regras, deve fazer em conformidade com dentro do espectro da delegação legislativa da Lei 6.385/76 e, eventualmente, na Lei 6.404/76. Além disso, o conteúdo das suas regras administrativas deve respeitar a hierarquia das normas e não confrontar preceitos constitucionais ou da legislação infraconstitucional.

Para o exercício da sua atividade normativa, o colegiado da CVM poderá iniciar audiências públicas para ouvir os participantes do mercado e afetados pela nova regra. ${ }^{37}$ Esta é uma prática adotada pela agência reguladora que é bastante bem vista, pela transparência que é dada às suas opções para a regulação de temas da sua competência. Conforme normativo recente, na fase de pré-audiência pública, são conduzidos estudos e análises para avaliar a pertinência e aderência de nova regulação e o documento final a ser disponibilizado ao público deve conter a motivação para a proposta identificando pontos de maior relevância.

37 Poder conferido pelo Regimento Interno da CVM, nos termos da Portaria do Ministério da Fazenda n. 327, de 11 de julho de 1997, especificamente, nos seus artigos 26 e 27. Mais recentemente foi detalhado o processo de regulação pela Portaria/CVM/PTE/ No. 170, de 16 de outubro de 2014. Neste normativo são indicadas as fases do processo (pré-audiência pública; audiência pública e pós-audiência pública). Disponivel em: <http://www.cvm.gov.br/ export/sites/cvm/audiencias_publicas/Portaria_170-14-Regulacao. pdf $>$. Acesso em: 12 out. 2015. 
Observando o É dentro deste seu poder normativo - e o aspecto motivacional acima indicado - que a CVM tem a possibilidade de adotar os padrões regulatórios produzidos pela IOSCO e outras instituições ou países integrantes da rede, sempre respeitando a delegação legislativa, bem como os procedimentos e justificações adotados para a criação de novas regras administrativas. A aprovação da regra por meio de uma agência reguladora competente parece facilitar a adoção de padrões internacionais. Com isso, evita-se a burocracia do processo legislativo e de todos em embates de interesses conflitantes na criação de uma nova lei, além não precisar encontrar lugar na agenda política do Congresso Nacional. Nessa altura, portanto, parece importante conhecer os mecanismos que a CVM utiliza para a apropriação dos padrões regulatórios da IOSCO.

\subsubsection{Processo de internalização dos padrões regulatórios da IOSCO}

Inicialmente, cabe apontar que os princípios e recomendações da IOSCO entram na ordem jurídica doméstica por distintas modalidades. Uma delas ocorre no momento em que, por ocasião da aprovação de um normativo (instrução, deliberação etc.), a CVM registra, na justificativa da regra ou no seu corpo, o atendimento aos padrões da IOSCO. Isto interessa quando a recomendação da IOSCO assume - no arcabouço regulatório brasileiro - um caráter cogente e vinculante para os participantes do mercado a que a norma se destina ${ }^{38}$. Mas, mesmo quando não tem caráter vinculante, a simples menção à recomendação da IOSCO gera um ganho reputacional, que é aproveitado pelo regulador doméstico.

\section{a) Diferentes formas e intensidades na apro- priação das recomendações da IOSCO pela CVM}

$\mathrm{Na}$ atividade normativa da CVM, nota-se que alguns documentos fazem menção expressa a estudos e recomendações da IOSCO. Em levantamento dos anos de 2005 a $2014^{39}$, encontra-se a existência de 198 Editais

38 Conforme o Relatório Anual da CVM de 2014, p. 114 "uma vez que as recomendações são definidas nos organismos acima citados, espera-se que os países membros adotem-nas." COMISSÃO DE VALORES MOBILIÁRIOS. Relatório anual da CVM de 2014. p. 116-121. Disponível em <http://www.cvm.gov.br/export/sites/ cvm/publicacao/relatorio_anual/anexos/Relatorio_Anual_2014. pdf $>$. Acesso em: 12 out. 2015.

39 O ano inicial de 2005 foi escolhido em razão das informações disponibilizadas na CVM sobre as audiências públicas relativas às normas do mercado de valores mobiliários iniciarem-se neste ano de Audiências Públicas, documentos que são divulgados antes da edição de novas normas e que contém, além do conteúdo das regras, justificativas e racionalidades utilizadas na sua proposição. Desse total de Editais, 19 deles fizeram, de algum modo, referência à posição da IOSCO.

$\mathrm{Na}$ análise desses Editais e dos documentos relativos à tramitação da audiência pública, é possível vislumbrar de que forma a regulação do mercado de valores mobiliários brasileiro se apropria dos debates e conclusões dos foros da IOSCO. Essa apropriação pode ser comprovada por meio das referências feitas ao conteúdo dos padrões internacionais, e, ainda, em função de outras variáveis, como a intensidade da linguagem utilizada, os documentos-fonte utilizados, e, por fim, o lapso temporal decorrido entre a divulgação da recomendação internacional da IOSCO e a divulgação do Edital/ norma final pela CVM. ${ }^{40}$

Quanto às referências feitas, de uma maneira geral, verificou-se que a CVM se apropria do padrão normativo internacional da IOSCO de formas distintas:

1) no corpo do texto ou em notas de rodapé dos
Editais de Audiência Pública, mas apenas para dar
ciência ao leitor de estudo que tenha abordado o
tema da nova norma. Nesta situação, encontrou-se
onze Editais; ${ }^{41}$
2) menção de que o novo normativo pretende
adotar padrão recomendado pela IOSCO. Com esta
utilização, foram encontrados quatro Editais; ${ }^{42}$
3) indicação expressa sobre a obrigação dos
regulados observarem princípios da IOSCO, sendo

(Cf. Disponível em: <http://www.cvm.gov.br/audiencias_publicas/index.html. Acesso em: out. 2015.

40 Vide análise mais detalhada em RACHMAN, Nora; PRADO, Viviane M; COELHO, Alexandre R. Internalização dos padrões regulatórios internacionais no Brasil: o caso IOSCO. 2015. (no prelo).

41 Nesse sentido, ver: (1) Edital CVM 03/2006, que resultou na Instrução CVM 450/07; (2) Edital CVM 06/2007, que resultou na Instrução CVM 461/07; (3) Edital CVM 04/2009, que resultou nas Instruções CVM 505/11 e 506/11; (4) Edital CVM 05/2009, que resultou na Instrução CVM 484/10; (5) Edital CVM 05/2010, que resultou na Instrução CVM 538/13; (6) Edital CVM 15/2011, que resultou na Instrução CVM 539/13; (7) Edital CVM 03/2013, que resultou na Instrução CVM 552/14; (8) Edital CVM 05/2013, que foi encerrada sem edição de norma; (9) Edital CVM 06/2013, que resultou nas Instruções CVM 541/13, 542/13 e 543/13; (10) Edital CVM 04/2014, que resultou na Instrução CVM 555/14; (11) Edital CVM 13/2014, sem edição de norma até o momento.

42 Essa situação refere-se aos seguintes editais: (1) Edital CVM 07/2008, que resultou na Instrução CVM 480/09; (2) Edital CVM 06/2011, que resultou na Instrução CVM 522/12; (3) Edital CVM 10/2011, que resultou na Instrução CVM 512/11; (4) Edital CVM $11 / 2013$, sem edição de norma até o momento. 
que foi encontrado apenas um Edital com esta força na adoção completa do padrão internacional ${ }^{43} \mathrm{e}$

4) referência a participantes (investidores, emissores) que sejam regulados e supervisionados por autoridades que tenham celebrado o Memorando Multilateral de Entendimentos $(\mathrm{MMoU})$ auspiciado pela $\mathrm{IOSCO}^{44}$. Aqui são três Editais. ${ }^{45}$

Pela linguagem utilizada, nota-se a diferença de intensidade com que a CVM adota o padrão internacional. Em alguns momentos, aparece a clara indicação de que a CVM utiliza recomendações e estudos da IOSCO como fonte para a sua atividade normativa, o que ocorre sob a forma de inspiração para que seja dado um tratamento normativo à matéria, ou ainda, sob a forma de alinhamento do regramento doméstico aos padrões da IOSCO. ${ }^{46}$

Outra informação importante é a identificação do tipo de documento da IOSCO que serve como referência para a CVM apresentar, aos agentes de mercado brasileiros, as novas normas a serem editadas. Verifica-se que os documentos mencionados são tanto Relatórios de Consultas de minutas de documentos tornados públicos pela IOSCO para recebimento de comentários (Consultation Reports), Relatórios finais de grupos de trabalho, de forças-tarefa ou de Comitês da IOSCO (Final Reports), Estudos ou Princípios sobre temas específicos ou, até mesmo, Anúncios de Divulgação (Press releases).

Outro dado interessante identificado é o lapso temporal decorrido entre a discussão internacional e a referência na norma doméstica, até mesmo para identificar

43 Ver: Edital CVM 16/2011, que resultou na Instrução CVM $521 / 12$.

44 O Memorando Multilateral de Entendimentos (MMoU) estabelece um formato padronizado para cooperação e intercâmbio de informações sigilosas entre autoridades reguladoras do mercado de capitais de diversos países, especialmente para fins investigativos. A IOSCO tem um processo de análise e aprovação das autoridades interessadas em assinar o MMoU e atualmente conta com a adesão de mais de $82 \%$ das autoridades reguladoras membros da IOSCO.

45 Situações que estão refletidas nos seguintes documentos: (1) Edital CVM 02/2006, que resultou na Instrução CVM 431/06; (2) Edital CVM 05/2007, que resultou na Instrução CVM 465/08; (3) Edital CVM 12/2014, que resultou na Instrução CVM 560/15.

46 A redação usada pela CVM menciona as seguintes expressões: as propostas (de normas) "estão alinhadas com recomendações da IOSCO" ou "incorporam as novas recomendações da IOSCO", ou foram elaboradas "com inspiração nas práticas internacionais de regulação, conforme divulgadas pela IOSCO “. Por vezes menciona-se "estudos publicados por organismos internacionais", "um compromisso assumido internacionalmente pelo Brasil $[\ldots]$ perante a IOSCO" e, ainda, que se deve "observar os Princípios [...] da IOSCO”. a existência de uma relação causal entre ambas. Em relação à análise feita com os casos reais, verificou-se que nem sempre há concomitância do debate internacional com a referência à inovação da regulação nacional. $\mathrm{O}$ menor transcurso de prazo foi de um mês e o maior foi de 09 anos e cinco meses.

O que esses dados parecem apontar com relação à apropriação das recomendações da IOSCO na atividade regulatória por parte da CVM?

Quanto à linguagem utilizada, são mencionados os entendimentos alcançados na IOSCO ou as recomendações formuladas nesse foro. Porém, qual seria o motivo dessa referência, sempre que tais documentos não têm força vinculante? Uma das respostas possíveis está na via reputacional e como isto pode facilitar a aceitação da norma doméstica por agentes que participam em um mercado cada vez mais globalizado, ao utilizar-se do 'argumento IOSCO'. ${ }^{47}$

Seja pela reputação seja por mera referência, parece ter ficado evidente que não é mais possível pensar na regulação do mercado de valores mobiliários brasileiro considerando apenas os limites territoriais e as questões domésticas. ${ }^{48}$

Quanto à menção IOSCO como fonte nos processos normativos CVM, percebe-se que muitos dos documentos citados foram preparados em Comitês da IOSCO (Comitê Técnico, de Trabalho) e se encontram em fases distintas de finalização. Essa pode ser uma indicação de que é preciso voltar os olhos para como funcionam os foros de discussão internos na IOSCO, sua forma de governança e de adoção de padrões, e, principalmente, para o que está presente em sua agenda de discussão. Este conhecimento pode ser relevante para saber de onde e em que contexto surgem as inspirações para o regulador brasileiro.

Por fim, com relação ao decurso de tempo decorrido

47 Esse aspecto reputacional aparece claramente em defesa formulada pela CVM na ação judicial que questionou a constitucionalidade da obrigação de se divulgar o valor das remunerações dos administradores de companhias abertas. Vide item 5.2.2. abaixo.

48 Esse fenômeno aparece em CAFAGGI, Fabrizio. The architecture of transnational private regulation: EUI working papers, Law 2011/12. Italy: Department of Law. Disponível em: <http://cadmus.eui.eu/ handle/1814/18256>. Acesso: 12 out. 2015. e em CAFAGGI, Fabrizio. New foundation of transnational private regulation: EUI working papers. Italy: Robert Schuman Center for Advanced Studies. Private Regulation. (Series 04) Disponível em: <http://cadmus.eui.eu/bitstream/handle/1814/15284/RSCAS_2010_53.pdf? sequence $=1>$. Acesso em: 12 out.2015. 
entre a formulação ou aprovação do padrão internacional e a menção por parte do regulador brasileiro, não há um padrão específico observado. Isso pode indicar apenas a busca, pela CVM, do momento mais adequado para inserir o debate internacional na agenda regulatória brasileira.

\section{b) Questionamento do poder normativo da CVM para internalização dos padrões regulatórios e participação do poder judiciário}

Embora os limites territoriais pareçam não estar mais unicamente restritos ao doméstico, nem sempre pode-se aceitar como suficientes as premissas constantes do debate internacional. Afinal, o que é a IOSCO para o Brasil? Muitos elementos que integram as recomendações formuladas no âmbito da IOSCO não compõem a nossa realidade. Há uma carga de discussão em todas as recomendações internacionais, e é fundamental conhecer as raízes dessa discussão, ver, por exemplo, quais são os pontos que foram trazidos por reguladores de outros países, como Estados Unidos e Europa, como reação e configuração de seus modelos regulatórios.

O que interessa, ao fim e ao cabo, é conhecer as ideias fundantes das recomendações, para saber quanto desse debate está sendo refletido no cenário domésti$\mathrm{co}^{49} \mathrm{E}$, em especial, se o teor das recomendações precisa, no processo de internalização, de uma adequação do seu conteúdo às especificidades locais.

Essa parece ter sido a situação que deu ensejo a uma discussão travada, no Brasil, por ocasião da aprovação de regra que, seguindo o padrão internacional, prevê requisitos de transparência na divulgação da remuneração dos administradores de companhias abertas. ${ }^{50}$

Em primeiro lugar, competia verificar se, no processo de internalização, a nova regra estava de acordo com as demais regras e a hierarquia do sistema jurídico, tendo em vista especialmente as limitações do poder normativo da CVM. Neste caso específico, isto efetivamente ocorreu.

49 A pergunta que surge quando se pensa no conteúdo das normas internacionais e harmonização da regulação financeira diz respeito à tão controvertida ideia de one siže fits all.

50 Vide descrição desta tramitação em PRADO, Viviane M; SAMPAIO, Luiza S. Enforcing international financial standards in Brazil: limits and possibilities for adoption of IOSCO principles. Disponível em: <http://bibliotecadigital.fgv.br/ dspace/bitstream/handle/10438/11839/RPS_95_versão\%202. pdf? sequence $=1$ \&isAllowed=y $>$. Acesso em: 12 out. 2015.
No processo de adoção dessa regra específica, a CVM procedeu ao processo de audiência pública que tinha, por fim, abrir o debate para a oitiva dos agentes de mercado. Como resultado dessa audiência, a CVM reconheceu os limites do mercado e dos seus interesses e restringiu o âmbito de transparência de informações sobre remuneração dos administradores, por entender que assim estaria dando uma resposta aos anseios de determinados agentes do mercado, especificamente, os executivos de companhias abertas. ${ }^{51}$

O caso da transparência da remuneração dos administradores trouxe uma nova variável: a participação do Poder Judiciário, que é instituição externa ao mercado de valores mobiliários, mas interna ao sistema jurídico nacional e responsável pela aplicação das normas societárias e do mercado de capitais.

Para entender melhor como o Poder Judiciário foi trazido ao caso, é importante lembrar que a regra em questão foi aprovada por meio da Instrução CVM n ${ }^{\circ}$ 480/2010, que, além de dispor sobre informações da própria empresa, requer a divulgação de cifras e dados pessoais relevantes das pessoas que ocupam cargos de administração. De um lado, estava o legítimo interesse dos investidores de saber a política de remuneração dos gestores das companhias investidas. De outro lado, os administradores com o também legítimo interesse em não ter divulgados os seus dados financeiros. O caso foi levado para discussão em processo judicial movido pelo Instituto Brasileiro de Executivos de Finanças - IBEF contra a CVM, com medida limitar suportando a não divulgação por alguns que se beneficiam da decisão do STJ. ${ }^{52}$

51 Nesse caso, a partir de manifestações de interesses locais, contrários à transparência sobre a remuneração individual, modificou-se a exigência de divulgação para a informação pública de valores que demonstrassem o valor máximo, o mínimo e a média da remuneração paga aos administradores. Então, a regra ficou mais frouxa para ser o primeiro passo de transparência de tema tão controvertido no Brasil.

52 Documentos e decisões sobre este processo, ver: Petição inicial. Disponível em: <http://s.conjur.com.br/dl/peticao-suspensao-in-480-cvm.pdf>. Acesso em: 12 set. 2015.

BRASIL. Superior Tribunal de Justiça. Suspensão de liminar e de sentença n. 1210, do Tribunal Regional Federal da $2^{\mathrm{a}}$ Região, Rio de Janeiro, 29 de março de 2010. Disponível em: <https://ww2.stj.jus. $\mathrm{br} /$ processo $/$ pesquisa $/$ ?num_registro $=201000498520 \&$ aplicacao $=$ processos >. Acesso em: 12 set. 2015. Para informações sobre os recursos, ver ficha do caso disponível em: <https://ww2.stj.jus.br/ processo $/$ pesquisa $/$ ?num_registro $=201000498520 \&$ aplicacao $=$ pro cessos>. Acesso:15 jun. 2015. 
O interessante desse caso, mais do que tentar verificar a legitimidade ou fragilidade dos argumentos levantados, é entender o confronto (ou a possível compatibilização) entre o padrão internacional de divulgação de remuneração dos administradores e aspectos locais levados ao Poder Judiciário. Existem limites a serem observados na adequação da importação de regras globais para o sistema jurídico brasileiro?

Duas conclusões parecem transparecer sobre essa questão. Primeira, que a participação de outra instituição local (neste caso, o Poder Judiciário) pode trazer um outro ponto de vista aos padrões internacionais e a ponderação com outros interesses merecedores de proteção. E segunda, que a recepção de regras aceitas internacionalmente, por si só, não é capaz de dizer como as coisas funcionarão. É preciso pensar em normas que poderão passar por instituições e terão que dialogar com outras regras do nosso sistema jurídico. ${ }^{53} \mathrm{O}$ resultado pode não ter sido o querido ou previsto no momento da edição da norma com inspiração exclusiva em mercados externos. ${ }^{54}$

\section{c) Outros caminhos que aparecem na regulação do mercado de valores mobiliários}

Um último ponto importante a ser mencionado é que os processos de internalização de padrões internacionais no mercado de valores mobiliários brasileiro nem sempre ocorrem por intermédio de regras editadas pela CVM.

A esse respeito, citem-se alterações ocorridas na Lei ${ }^{\circ}$ 6.404/76 (lei das sociedades por ações) e que passaram, portanto, por um processo legislativo próprio no Congresso Nacional. Este foi o caso da Lei $n^{\circ}$ 11.638/2007, que integrou o padrão contábil das companhias brasileiras à norma internacional de contabili-

53 Sobre a posição do poder judiciário em temas internacionais, especificamente, o Supremo Tribunal Federal, mas em tema sobre liberdade de expressão, consultar: LOPES, Carla Patrícia F. Nogueira. Internalização do direito e pluralism jurídico: limites de cooperação no diálogo de juízes. Revista de Direito Internacional, Brasília, v.9, n. 4, p. 229-247, 2012.

54 Isso não é algo exclusivo do Brasil. Sobre a experiência internacional, vide MILHAUPT, Curtis J.; PISTOR, Katharina. Law \& capitalism: what corporate crises reveal about legal systems and economic development around the world. Chicago; Londres: University of Chicago Press, 2008. Os autores demonstram que padrões internacionais de governança corporativa ganham contornos próprios quando questionados em instituições locais. dade, a IFRS.

Outro caso é a apropriação de padrões internacionais por meio de regras de entidades autorreguladoras, no caso a ANBIMA e a BM\&FBOVESPA, que aprovam regras de regulação privada, ou seja, que não passam por processos de aprovação por parte da agência reguladora. Nesta categoria, mencione-se a imposição de requisitos, aplicáveis às instituições intermediárias do mercado, relativos ao dever de verificação de adequação dos produtos financeiros às condições financeiras do cliente (chamadas de regras de "suitability"). ${ }^{55}$ Nesse tema, as primeiras normas vieram da autorregulação da ANBIMA para depois serem incorporadas em regra da CVM pela Instrução CVM 539/2013. Mencione-se ainda, a exigência, pela BM\&FBOVESPA, de requisitos de governança corporativa para a listagem de companhias no mercado de bolsa. ${ }^{56}$

Constata-se, assim, que os padrões internacionais podem entrar no país por regulação estatal ou privada. O que é importante destacar é que, no caso da regulação privada, as entidades autorreguladoras responsáveis pela transposição do padrão internacional para o Brasil (ANBIMA e BM\&FBOVESPA) participam ativamente no foro no qual foi inspirada a regra, isto é, a IOSCO. Mesmo o caso de adoção do IFRS, que se deu por legislação federal, houve forte atuação da CVM para que houvesse aprovação da lei para melhorar o padrão contábil adotado pelas empresas nacionais.

Em síntese, a experiência brasileira demonstra que a agência reguladora do mercado de valores mobiliários é a principal porta de entrada das recomendações internacionais. Mas não é a única, tendo relevância também as entidades autorreguladoras e os agentes privados, bem como o legislador.

55 ASSOCIAÇÃO BRASILEIRA DAS ENTIDADES DOS MERCADOS FINANCEIRO E DE CAPITAIS. Parecer de orientaşão 14/09, Circular de Supervisão 2010/04 e 2010/0. Disponíveis em: <http://portal.anbima.com.br/autorregulacao/supervisao/ circulares-supervisao/Pages/circulares-supervisao.aspx $>$. Acesso: 12 set. 2015.

56 É o caso das regras de listagem de companhias abertas, aprovadas pela Bolsa de Valores brasileira, a BM\&FBovespa, no segmento de listagem conhecido como Novo Mercado. Regulamentos. Disponíveis em: <http://bmfbovespa.com.br/pt-br/servicos/download/Regulamento-de-Listagem-do-Novo-Mercado.pdf $>$. Acesso: out. 2015. 


\section{Considerações finais}

Mesmo aceitando que os produtos regulatórios transnacionais não fazem parte da ordem jurídica internacional, o estudo do caso da implementação da regulação da IOSCO pela CVM sugere a relevância da produção normativa fora dos mecanismos tradicionais do direito internacional.

O estudo do caso revelou que a IOSCO faz parte de uma rede de organizações transnacionais que, apesar de não ser formalmente considerada como organização com personalidade jurídica internacional, chama a atenção por ter o objetivo de apontar soluções normativas e de harmonizar as regulações fragmentadas em vários estados nacionais sobre mercados financeiros e de valores mobiliários. A sua importância ficou mais evidente após a crise financeira de 2008.

O Brasil está representado nessa rede transnacional com a participação da CVM, que desde 2008 vem tendo presença mais ativa nos comitês técnicos da IOSCO e foi chamada a ser membro de outros foros como, por exemplo, o FSB. Na atividade regulatória da CVM, identifica-se referência aos produtos da IOSCO, ainda que seja com intensidades diferentes. Em várias passagens, visualiza-se que padrões internacionais servem como argumento para legitimar a escolha da nova norma e indicar o prestígio em segui-los.

Essa implementação dos produtos da IOSCO deve se obedecer o poder regulador da CVM, considerando o desenho institucional, os limites da delegação normativa previstos em lei e o respeito ao disposto em normas jurídicas constitucionais e infraconstitucionais. A accountability sobre a incorporação dos produtos regulatórios deve ser analisada a partir dos mecanismos de transparência e de prestação de contas da própria agência reguladora no exercício da sua atividade normativa. É no processo de edição de uma nova regra que se nota, nos documentos das audiências públicas e seus relatórios, que os instrumentos de transparência aparecem. O controle do poder normativo somente pode se dar a posteriori, pela atuação do Poder Judiciário, se for provocado a se pronunciar sobre a legalidade ou constitucionalidade da nova regra que incorpora padrões originários de foros transnacionais.

A indicação da inspiração da regra em padrões internacionais suscita a dúvida se este fenômeno representa a transferência do poder normativo do plano domésti- co para as redes transnacionais. E desta dúvida surgem outras ainda mais relevantes, que devem ser objeto de pesquisas futuras. Uma delas é quanto à legitimidade destes foros transnacionais para definir padrões internacionalmente aceitos. A segunda é se os mecanismos de accountability utilizados pela CVM e revelados no estudo de caso podem ser comparados com outros existentes em diferentes setores regulados, ou, ainda, com mecanismos de legitimação contidos no sistema jurídico como um todo.

\section{REFERÊNCIAS BIBLIOGRÁFICAS}

ASSOCIAÇÃO BRASILEIRA DAS ENTIDADES DOS MERCADOS FINANCEIRO E DE CAPITAIS. Parecer de orientação 14/09, Circular de Supervisão 2010/04 e 2010/0. Disponíveis em: <http://portal.anbima.com. $\mathrm{br} /$ autorregulacao/supervisao/circulares-supervisao/ Pages/circulares-supervisao.aspx $>$. Acesso: 12 set. 2015.

BRASIL. Superior Tribunal de Justiça. Suspensão de liminar e de sentença n. 1210, do Tribunal Regional Federal da $2^{a}$ Região, Rio de Janeiro, 29 de março de 2010. Disponível em: <https://ww2.stj.jus.br/processo/ pesquisa $/$ ?num_registro $=201000498520 \&$ aplicacao $=p$ rocessos >. Acesso em: 12 set. 2015.

BRUMMER, Chris. Soft law and the global financial system: rule making in the 21 st century. Cambridge: Cambridge University Press, 2012.

BÜTHE, Tim; MATTLI, Walter. The new global rulers: the privatization of regulation in the world econ:omy. Princeton: Princeton University Press, 2011.

CAFAGGI, Fabrizio. New foundation of transnational private regulation: EUI working papers. Italy: Robert Schuman Center for Advanced Studies. Private Regulation. (Series 04) Disponível em: <http://cadmus.eui. eu/bitstream/handle/1814/15284/RSCAS_2010_53. pdf? sequence=1>. Acesso em: 12 out. 2015.

CAFAGGI, Fabrizio. The architecture of transnational private regulation: EUI working papers, Law 2011/12. Italy: Department of Law. Disponível em: < http://cadmus. eui.eu/handle/1814/18256>. Acesso: 12 out. 2015.

COMISSÃO DE VALORES MOBILIÁRIOS. Relatório anual da CVM de 2014. Disponível em <http://www. cvm.gov.br/export/sites/cvm/publicacao/relatorio_ 
anual/anexos/Relatorio_Anual_2014.pdf>. Acesso em: 12 out. 2015

COMISSÃO DE VALORES MOBILIÁRIOS. Relatório anual de 2008. Disponível em: <http://www.cvm.gov. $\mathrm{br} /$ export/sites/cvm/publicacao/relatorio_anual/ anexos/Relatorio_Anual_2008.pdf>. Acesso em: 12 out. 2015

COMISSÃO DE VALORES MOBILIÁRIOS. Relatório anual de 2009. Disponível em: <http://www.cvm.gov. $\mathrm{br} /$ export/sites/cvm/publicacao/relatorio_anual/ anexos/Relatorio_Anual_2009.pdf>. Acesso em: 12 out. 2015

COMISSÃO DE VALORES MOBILIÁRIOS. Relatório anual de 2010. Disponível em: <http://www.cvm.gov. $\mathrm{br} /$ export/sites/cvm/publicacao/relatorio_anual/ anexos/Relatorio_Anual_2010.pdf>. Acesso em: 14 out. 2015

COMISSÃO DE VALORES MOBILIÁRIOS. Relatório anual de 2011. Disponível em: <http://www.crm.gov. $\mathrm{br} /$ export/sites/cvm/publicacao/relatorio_anual/ anexos/Relatorio_Anual_2011.pdf>. Acesso em: 12 out. 2015

COMISSÃO DE VALORES MOBILIÁRIOS. Relatório anual de 2012. Disponível em: <http://www.cvm.gov. $\mathrm{br} /$ export/sites/cvm/publicacao/relatorio_anual/ anexos/Relatorio_Anual_2012.pdf>. Acesso em: 12 out. 2015

COMISSÃO DE VALORES MOBILIÁRIOS. Relatório anual de 2013. Disponível em: <http://www.cvm.gov. $\mathrm{br} /$ export/sites/cvm/publicacao/relatorio_anual/ anexos/Relatorio_Anual_2013.pdf>. Acesso em: 12 out. 2015

ELIAS, Fernando Lopes Ferraz. A internacionalização do direito a partir de diferentes fenômenos privados de construção normativa. Revista de Direito Internacional, Brasilia, v. 11, n. 1, p. 1136-1163, 2013.

HELLEINER, Eric; PAGLIARI Stefano. The end of an era in international financial regulation? a postcrisis research agenda. International Organization 65, 2011, p. 170. Disponível em: < http://www.stefanopagliari.net/helleiner_pagliari_-_the.pdf $>$ Acesso em: 12 out. de 2015.

HELLEINER, Eric; PAGLIARI Stefano; ZIMMERMAN, H (Eds.). Global finance in crisis: the politics of international regulatory change. London: Routledge, 2010.
HIIL INNOVATING JUSTICE. Research project informal international law-making. Disponível em: $<$ http://www.hiil.org/project/informal-internationallaw-making-and-accountability $>$. Acesso em: 12 out. 2015.

INSTITUTE FOR INTERNATIONAL LAW AND JUSTICE. Global administrative law project. Disponível em: <http://www.iilj.org/gal/>. Acesso em: 12 out. 2015.

INTERNATIONAL ORGANIZATION OF SECURITIES COMMISSIONS. AboutIOSCO. Disponível em: $<$ http://www.iosco.org/about/?subsection=about_iosco >. Acesso em: out. de 2015.

INTERNATIONAL ORGANIZATION OF SECURITIES COMMISSIONS. Estatuto social. Disponível em: <http://www.iosco.org/library/by_laws/pdf/IOSCO-By-Laws-Section-1-English.pdf $>$. Acesso em: 12 out. 2015.

INTERNATIONAL ORGANIZATION OF SECURITIES COMMISSIONS. Joint Forum. Disponível em: $<$ https://www.iosco.org/about/?subsection=joint_forum>.> Acesso em: 12 Out. 2015.

INTERNATIONAL ORGANIZATION OF SECURITIES. Multilateral memorandum of understanding concerning consulation and cooperation and the exchange of information (IOSCO MMOU). Disponível em: <http://www.iosco. org $/$ about $/$ ?subSection $=$ mmou\&subSection $1=$ signato ries>. Acesso em: 12 out. 2015.

INTERNATIONAL ORGANIZATION OF SECURITIES COMMISSIONS. Objectives and principles of securities regulation. Disponível em: <http://www.iosco.org/ library/pubdocs/pdf/IOSCOPD82.pdf $>$. Acesso em: 12 out. 2015.

INTERNATIONAL ORGANIZATION OF SECURITIES COMMISSIONS. Principles assesment methodology. Disponível em: <http://www.iosco.org/library/ pubdocs/pdf/IOSCOPD359.pdf>. Acesso em: out. 2015.

INTERNATIONAL ORGANIZATION OF SECURITIES COMMISSIONS. Relatório Anual da IOSCO 2011. Disponível em: < https://www.iosco.org/annual_ reports/2011/>. Acesso em: 12 out. 2015.

KINGSBURY, B.; KRISCH, S.; STEWART, R. The Emergence of global administrative law: Law and Contemporary Problems, v. 68, p. 15-61, 2005. 
LOPES, Carla Patrícia F. Nogueira. Internalização do direito e pluralism jurídico: limites de cooperação no diálogo de juízes. Revista de Direito Internacional, Brasília, v.9, n. 4, p. 229-247, 2012.

MILHAUPT, Curtis J.; PISTOR, Katharina. Law \& capitalism: what corporate crises reveal about legal systems and economic development around the world. Chicago; Londres: University of Chicago Press, 2008.

NASSER, S. H.; MACHADO, A. M. F. Informal International lawmaking and accountability in Brazil. In: BERNAN, A. et al. (Ed). Informal international lawmaking: case studies: the Hague: Torkel Opsahl Academic EPublisher, 2012. p.141 - 178.

NASSER, Salem H. Fontes e normas do direito internacional: um estudo sobre a soft law. 2. ed. São Paulo: Atlas, 2006.

PRADO, Viviane M; SAMPAIO, Luiza S. Enforcing international financial standards in Brazil: limits and possibilities for adoption of IOSCO principles. Disponível em: $\quad<$ http://bibliotecadigital.fgv.br/dspace/ bitstream/handle/10438/11839/RPS_95_versão\%202. pdf? sequence $=1$ \&isAllowed $=\mathrm{y}>$. Acesso em: 12 out. 2015.

RACHMAN, Nora; PRADO, Viviane M; COELHO, Alexandre R. Internalização dos padrões regulatórios internacionais no Brasil: o caso IOSCO. 2015. (no prelo).

SLAUGHTER, Anne-Marie. Everyday global governance. Research Library Core, v. 132, n. 1, p. 83-90, 2003.

VERDIER, Pierre-Hugues. The political economy of international financial regulation. Indiana Law Journal, v. 88, p. 1461, 2013.

VERDIER, Pierre-Hugues. Transnational regulatory network and their limits. The Yale Journal of International Law, v. 34, n. 1, p. 113-172, 2009.

ZARING, David. Finding legal principle in global financial regulation. Journal of International Law, Virginia, v.53, n.3, p. 683-721. 
Para publicar na Revista de Direito Internacional, acesse o endereço eletrônico www.rdi.uniceub.br ou www.brazilianjournal.org.

Observe as normas de publicação, para facilitar e agilizar o trabalho de edição. 